\title{
Optimism and commitment: an elementary theory of bargaining and war
}

\author{
Clara Ponsati · Santiago Sanchez-Pages
}

Received: 14 November 2010 / Accepted: 30 June 2011 / Published online: 15 July 2011 (C) The Author(s) 2011. This article is published with open access at SpringerLink.com

\begin{abstract}
We propose an elementary theory of wars fought by fully rational contenders that features three of the main rationalist explanations for armed conflicts: uncertainty, commitment, and indivisibility. Two parties play a Markov game that combines stages of bargaining, where offers are made, with claim stages, where one side can commit to impose surrender on the other. Under uncertainty on the persistence of claims, long confrontations occur in the unique equilibrium of the game: war arises when reality disappoints initial (rational) optimism, and it persists when both agents are optimists but reality proves both wrong. Bargaining proposals that are rejected initially might eventually be accepted after several periods of confrontation. We provide an explicit computation of the equilibrium, evaluating the probability of war, and its expected losses as a function of (i) the costs of confrontation, (ii) the asymmetry of the split imposed under surrender, and (iii) the strengths of contenders at attack and defense. Changes in these parameters display non-monotonic effects.
\end{abstract}

Keywords Bargaining · Incomplete information · Commitment · Indivisibilities · War

\section{JEL Classification $\quad \mathrm{C} 78 \cdot \mathrm{D} 74$}

\section{Introduction}

We propose an elementary theory of wars fought by fully rational contenders. We focus on the frictions and impasses that take place during this type of disputes. On the one

\section{Ponsati}

Institut d'Anàlisi Econòmica-CSIC, 08193 Bellaterra, Barcelona, Spain

e-mail: clara.ponsati@iae.csic.es

\section{S. Sanchez-Pages ( $\varangle)$}

University of Barcelona and University of Edinburgh, Avda Diagonal 690, Barcelona 08034, Spain e-mail: sanchez-pages@ub.edu 
hand, countries often bargain under uncertainty because strength and power are hard to measure and prone to misrepresentation. On the other hand, wars are characterized by alternating periods of negotiation and hostilities in which parties fight, obtain or lose advantage, bargain and make demands to their opponents. These demands tend in addition to be very persistent. One reason for this is that countries sometimes fight over sacred places or symbolic enclaves over which concessions seem unacceptable. In other occasions, even if a wide range of concessions are feasible, countries commit to specific claims, due either to domestic political considerations or because claims can grant them strategic advantage. All these frictions often make countries reluctant to withdraw unreasonable claims and refuse bargaining until a protracted confrontation persuades them to do otherwise.

We build up a model that focuses on these distinctive features of war and that combines three of the main rationalist explanations for it: uncertainty, commitment and indivisibility. We consider a set-up in which two parties must resolve a dispute that could potentially go on for ever. The existence of phases of negotiation and fighting is modelled as a multi-stage Markov game where over time players may find themselves in a bargaining state, where one party makes a proposal and its acceptance by the other party ends the game, or in a claim state, where bargaining is suspended and one of the parties is in the position of making a demand biased to her benefit. At that point, the game can terminate only if the opponent surrenders to such claim. Claims can only be reversed when the side that makes it is defeated in confrontation.

Claim states constitute one of the main innovations of our model so let us elaborate on their nature in more detail. Claims entail a specific division of the cake that can stem from (1) parties commitment or (2) from the nature of the issue. One of the main sources of commitment to specific demands is that contenders are actually non-unitary agents. Countries often raise claims thanks to the efforts of radical groups and because assessors feed only positive news to leaders who in turn tend to ignore negative information due to nationalism or patriotism. ${ }^{1}$ These biases difficult negotiations by narrowing down the set of possible agreements. Military operations such as troop movements and occupation of territories constitute another source of commitment because they trigger honor and reputational considerations. On the one hand, armies are trained to defend national honor, that is, to sustain commitment to claims - even when they are hopeless - regardless of the cost, and to maintain a reputation for doing so. ${ }^{2}$ On the other hand, willingly withdrawing a claim earned by force can also undermine an army's reputation, and this may be very costly in future or concurrent conflicts. Fearon (1994) suggests that leaders can strategically create this sort of audience costs in order to signal credibly their resolve given that backing down from claims can jeopardize their tenure. However, these costs may also lead to lock-in situations and force leaders to wage war. Schultz (1998) points out that the existence of domestic political opposition can help to create commitment by pushing the government towards tough stances. This was the case of Democratic party in the

\footnotetext{
1 'While it is hard for a government, particularly a responsible government, to appear as irrational whenever such appearance is expedient, it is equally hard for a government, particularly a responsible one, to guarantee its own moderation in every circumstance.' (Schelling 1966, p. 41).

2 See O'Neil (1999).
} 
eve of the Spanish-American War, or the Liberal Party of Britain during the Fashoda crisis. Finally, Jackson and Morelli (2007) show that countries can go to war because of political bias, that is, the difference in incentives between the society as a whole and pivotal decision makers who can be inclined to make excessive demands.

Claims can also emerge from the (perceived) lack of divisibility of the issue in dispute. Claim states can be interpreted as situations in which one side has obtained the temporary military control of an item, a territory or landmark. Examples include oil fields (as in the case of Iraq's invasion of Kuwait in 1990), diamond mines, sacred places (Hassner 2003), territories considered as "homeland" (Toft 2006) or even office of a country (as in the War of Spanish Succession). Because their nature only one or few divisions of these objects are feasible. But as Goddard (2006) argues, indivisibility is not necessarily fixed. For instance, Jerusalem was not treated as indivisible by the early Israeli leadership; nor it was the sovereignty of Ireland until the twentieth century. ${ }^{3}$ Hence indivisibility can change with time or be overcome if parties agree to use transfers or compensations.

Coming back to the description of the model, rejection of proposals during bargaining states or opposition to claims during claim states make the game continue with the conflict unresolved. This is costly to both parties because it causes delay. In the following period, the state of the game can change from a bargaining state into a claim state, or vice-versa. These changes are randomly determined by transition probabilities which depend on the strength of each side. This feature is admittedly a reduced form of the processes mentioned above; our main focus is on the effects of these frictions on bargaining rather than on their causes. But random transitions between states also capture the inherent and prevalent randomness that defines military confrontations. As Clausewitz (1976) quite eloquently put it, "War is the province of chance."

Our analysis takes off with the characterization of equilibria under complete information, when the persistence of claims and the strength of the players are known. For any value of the parameters agreement prevails immediately in bargaining states. As usual in alternating-offer bargaining, the proposer offers a share that leaves the responder just indifferent to her continuation value upon confrontation, which is accepted. The (potential) gains attainable in claim states determine the terms of agreement, but players never resort to confrontation. Exploring the circumstances in which claims are effective and induce surrender provides the main insight of this part of the analysis: when a claim is established, either it induces surrender or else it is met by opposition until it is dismissed by force. Very extreme claims (relative to their persistence upon confrontation) give such a small payoff to the opponent that she never surrenders. Thus, when claims are sufficiently big, confrontation prevails at every period until the bargaining state is re-established. This observation becomes crucial when we address the effect of uncertainty and private information.

In the second part of the paper we drop the assumption that transitions between states are governed by publicly known probabilities and we introduce uncertainty. Incomplete information is one of the most prominent causes of conflict in bargaining (Sanchez-Pages 2011). Because power is difficult to observe and measure, parties

\footnotetext{
3 For Goddard (2006) indivisibility is the result of actors' choices that may leave them locked in bargaining positions. From that perspective, indivisibilities can be seen as the result of attaining commitment.
} 
typically ignore their strength in case of war and can only learn about it by fighting. In order to account for this type of friction, we consider two layers of uncertainty. One is that parties know their own type, hostile or lenient, but not the type of the opponent. Second, at bargaining states, countries do not know how likely they (nor their opponent) will be able to maintain control if the game moves to a claim state. They just know the distribution from which the persistence of claims will be drawn. This information becomes public when disagreement leads the game to a claim state.

Under these informational assumptions, war can arise even when the game starts in a bargaining state: In the unique equilibrium strategy profile a very rich range of outcomes may occur. These histories capture the different patterns that arise in realworld disputes. For one set of parameters parties exchange a number of offers and counteroffers before reaching an agreement. This is consistent with the observation that many interstate disputes do not entail actual hostilities, like the Second Moroccan Crisis of 1911 or the Cuban Missile Crisis in 1962. For natural parameter configurations war does start with positive probability. If the claim state does not induce immediate surrender because the claim is too large, a (potentially very long) phase of confrontation follows until the claim is dismissed. In bargaining states, proposals that are initially rejected may eventually be accepted after a long conflict. This was the case for instance in the negotiations between Egypt and Israel during the 70s or between the IRA and the British government in the 1990s.

The intuition for these results is the following. The power to sustain claims is always uncertain, but each party is privately informed about (the probability distribution of) her own power. Hostile (lenient) types have a high (low) expectation of claim persistence; and consequently expect high (low) payoffs in claim states. In bargaining states - before any claim is established - the proposer can extract a large share from a lenient responder because such type expects low returns from confrontation. Suppose that the prior probability that the opponent is a lenient type is high so that the proposer's optimism - her anticipation that she can get a large share-has rational basis. Then, in equilibrium, the proposer demands a share which is acceptable only by the lenient type. But when the responder turns out to be a hostile type, rejection follows and war takes place. If a claim is established in the sequel, and its realized persistence is insufficient to induce surrender, war will continue.

As we obtain a unique equilibrium, which is easily computed, our model allows precise comparative statics: We measure the effect of changes of the different parameters on the likelihood, duration and costs of war. We find that war occurs with positive probability provided that agents' belief that the opponent is a lenient type is greater than a given threshold. This threshold is increasing in the cost of confrontation, claims' size, and agents' strength. Thus, departing from situations where war occurs with positive probability, small parameter changes are irrelevant; but a sufficient increase drops the probability of war to zero. A similar non-monotonicity holds with respect to the losses of war. Our comparative statics on the likelihood and duration of wars are in line with the empirical evidence on the onset and termination of interstate conflicts.

The rest of the paper is organized as follows. Section 2 relates our work to the literature. The model is formally presented in Sect. 3. Section 4 discusses environments of complete information. The main results are in Sect. 5 where incomplete information is assumed. Proofs can be found in the Appendix. 


\section{Related literature}

The first formulation of war as a joint process of bargaining and fighting was due to Clausewitz in his treaty of 1832. Clausewitz's ideas inspired many others, most notably Blainey (1973) who was especially insightful in his analysis of the causes of war. He was the first one to argue that optimism about the own capabilities was behind most armed conflicts throughout history. In line with this, Wittman (1979) argued that increasing the probability of military victory can reduce the probability of agreement because the now stronger party becomes more demanding. Our results formally support these two intuitions.

Following Blainey, Wagner (2000) argues wars are processes by which parties learn each others' real forces and costs-thus opening the door to agreements that are impossible without war. Although he does not offer formal results, his discussion of the process by which wars start, develop and end is suggestive: wars commence because inconsistent expectations on the consequences of fighting initially prevent the existence of agreements that both parties prefer to confrontation; as fighting proceeds expectations are adjusted and mutual gains from agreement arise. ${ }^{4}$

These insights spawned a generation of bargaining models that explored these ideas formally. Filson and Werner (2002) discuss a very special (two-period, two-type) formulation, and emphasize the role of battlefield resource availability. Powell (2004) models war as a costly process of bargaining during which parties run the risk of military collapse; he considers uncertainties over either power or the cost of fighting, which allows comparisons of the learning processes induced in each case. SanchezPages (2009) examines the effects of limited confrontations on efficiency when they reveal information about the balance of power. In that case, battles have an ambiguous effect on welfare because they can help parties to become more realistic but they can also be used to obtain advantage at the bargaining table. The models proposed by Slantchev (2003) and Smith and Stam (2004) are the closest to ours. These authors build on Smith (1998) where, as in the present paper, war is a Markov game. Sides fight for the control of a number of forts and war terminates when one of the sides captures all of them. These papers focus on how these limited conflicts shape agreements and influence the duration of wars.

With the exception of Smith and Stam (2004), the models above assume onesided private information with common priors. They show that separating equilibria can be sustained and provide insights on the process of information revelation that unravels through war based on the properties of equilibria. However, as Powell (2004) emphasizes, these results are extremely sensitive to the details of the game or the equilibrium notion. A general problem in all these models is the great multiplicity of equilibria, which makes comparative statics very problematic. Furthermore, the assumption that one of the parties is fully informed has

\footnotetext{
4 The role of asymmetric information in fueling costly conflict is well known in the theoretic literature. Banks (1990), Bester and Warneryd (2006), Fearon (1995) and Powell (1996, 1999) propose game-theoretic analysis of war focusing on the role of asymmetric information in prompting disagreement in negotiations prior to fighting - taking war as an outside option. As war is considered a game-ending move, the scope of these models is limited to the analysis of the onset of war.
} 
such powerful implications that conclusions cannot extend to setups with twosided incomplete information. Smith and Stam (2004) argue that war arises due to disagreements on beliefs, and formulate such disagreement as different prior beliefs on military capabilities. Their approach is effective in supplying tractable and transparent predictions. Such predictions, however, rely on the specific details of these beliefs; this requires common knowledge of the non-common priors, an assumption which is inconsistent with any presumption of full rationality by the parties.

The present paper shares with Smith and Stam (2004) the premise that disagreements on beliefs are crucial, but maintains the analysis in the realm of Bayesian games with common priors. This comes at the price of being unable to explore the role of war as a process of information transmission; in our model private information triggers war, but it is commitment to claims what sustains its continuation. However, thanks to the simplicity of the informational set up, our model delivers a unique equilibrium which is straightforward to characterize, and allows a symmetric treatment of agents.

Claim states capture two other rationalist explanations for war. One is commitment. In the strategic literature, it has long been recognized that unilateral commitment awards advantage; and that attempts to attain commitment or to dismiss that of opponents' are a fundamental source of conflict (Crawford 1982; Schelling 1960). Another branch of the literature has highlighted the inability of states to commit to refrain from using force once they have obtained military advantage as a fundamental cause of war (Fearon 1995; Powell 2006). The second explanation is issue indivisibility: When the set of possible agreements that states can reach is small, their ability to strike a bargain that all parties prefer to war is severely limited. Toft (2006) argues that issue indivisibility is a truly distinctive cause of war and argues that it provides a better explanation of ethnic conflict than commitment or incomplete information problems. On the other hand, Powell (2006) argues that indivisibility is just one type of commitment problem; it is lack of commitment, not the inherent nature of the issue, what prevents states from expanding the set of possible agreements on an issue (by using lotteries, transfers or issue linkage). The present analysis remains agnostic on this debate. Both types of bargaining frictions can be present in our model via claim states.

Finally, the equilibrium of the game features a rich variety of outcomes that capture the variety of patterns in real-world disputes. As pointed out by Leventoglu and Tarar (2008), bargaining models of war rarely allow the possibility of an agreement being reached after a peaceful exchange of offers and counteroffers. Either agreement is immediate or conflict takes place. For a set of parameters, the equilibrium of the game entails an agreement being reached after some rounds of bargaining and without escalation. ${ }^{5}$ In other cases war follows after a failure of negotiations. This conflict may be long and full of "fortune reversals".

\footnotetext{
5 Some other mechanisms can deliver agreements without escalation. Schultz (1998) shows that domestic political competition can make government's threats credible under incomplete information. Bevia and Corchon (2010) explore the role of pre-war transfers as a conflict-prevention mechanism in the absence of commitment.
} 


\section{The game}

Two players $i=1,2$ must split one unit of surplus. Time is discrete $t=0,1,2, \ldots$ The state of the game establishes the moves available for each player at each date. There are four possible states, two bargaining states $s_{b i}$, where no player holds a claim and bargaining proceeds with an exchange of proposals, and two claim states, $s_{c i}$ in which one player holds a claim and bargaining is suspended. In state $s_{b i}$, player $i$ is the proposer, she chooses a proposal, any pair $\left(x_{i}, 1-x_{i}\right), 0 \leq x_{i} \leq 1$, then, player $j$, decides whether to accept or reject. On the other hand, in state $s_{c i}$, only player $j \neq i$ moves, and her choices are opposition or surrender. Surrender terminates the game, $i$ takes her claim $c_{i}, 1 / 2<c_{i} \leq 1$, and $j$ gets $1-c_{i}$. Upon rejection or opposition, one period of confrontation takes place and the game moves to the following period. When confrontation occurs at $t$ the state at $t+1, s_{t+1}$, is randomly determined with probabilities that depend on the state at $t, s_{t}$, according to the transition probability matrix of Table 1.

The parameters $q_{i t}$ and $1-p_{i t}$ measure $i$ 's strength, respectively at defense and attack: $q_{i t}$ is the probability that player $i$ will maintain her claim into period $t+1$ (i.e. the persistence of player $i$ 's claim at $t$ ) while $1-p_{i t}$ is the probability that player $i$ establishes a claim when she rejects a proposal in bargaining state $s_{b j}$. Alternatively, $1-p_{i t}$ can be interpreted as the probability that a hawkish leader or general comes into power and takes an intransigent stance on the issue in dispute. On the other hand, it is possible to interpret the value of persistence $q_{i t}$ also as the probability that the expected costs of backing down from a claim - either reputational or due to domestic audiences - or the costs of deposing a hawkish leader exceed a certain threshold and become prohibitive.

Confrontation is costly because players are impatient. The dispute terminates only with surrender in claim states, or else, in bargaining states, with an agreement. Upon a termination that allocates shares $\left(z_{i}, 1-z_{i}\right)$ at date $t$ agent $i$ obtains $\delta^{t} z_{i}$, with $0<\delta<1$. When the outcome of the game is perpetual confrontation both agents obtain 0 .

A history of the game at $t$ is a sequence of states of the game from 0 to $t$, the rejected proposals or opposed claims from 0 to $t-1$, and possibly a standing proposal. A strategy for player $i$, denoted $\sigma_{i}$, selects the action of player $i$ at each history in which she must move. A strategy profile is a subgame perfect equilibrium if, at every history, the actions of both players are mutually best responses. A strategy profile is stationary if

Table 1 The matrix of transition probabilities between states

\begin{tabular}{lllll}
\hline$\backslash^{t+1}$ & $s_{b 1}$ & $s_{b 2}$ & $s_{c 1}$ & $s_{c 2}$ \\
$s_{b 1}$ & $\frac{p_{2 t}}{2}$ & $\frac{p_{2 t}}{2}$ & 0 & $1-p_{2 t}$ \\
$s_{b 2}$ & $\frac{p_{1 t}}{2}$ & $\frac{p_{1 t}}{2}$ & $1-p_{1 t}$ & 0 \\
$s_{c 1}$ & $\frac{1-q_{1 t}}{2}$ & $\frac{1-q_{1 t}}{2}$ & $q_{1 t}$ & 0 \\
$s_{c 2}$ & $\frac{1-q_{2 t}}{2}$ & $\frac{1-q_{2 t}}{2}$ & 0 & $q_{2 t}$ \\
\hline
\end{tabular}


actions depend only on the state of the game. We use the term equilibrium to refer to a subgame perfect equilibrium in stationary strategies.

The present game is related to the general class of bargaining games studied in Merlo and Wilson (1995), where the set of admissible agreements and the bargaining protocol follow a Markov process. Unfortunately our analysis cannot build on theirs since their characterization of equilibria relies on the assumption that, at all states, agents can choose an agreement from a standard bargaining set; this assumption fails in our game because in claim states there is a unique feasible termination.

\section{Equilibria when strength is known}

Assume that transition probabilities are known and remain constant $q_{i t}=q_{i}, p_{i t}=p_{i}$ for all $t$, and let $0<q_{i t}, p_{i t} \leq 1, i=1,2$. Absorbing claim states correspond to the case where $q_{i}=1$. On the other hand, it is straightforward to see that when $p_{i}=1$, so claim states do not exist, peace prevails immediately with the split $\left(1-\frac{\delta}{2}, \frac{\delta}{2}\right)$.

Equilibrium outcomes and payoffs depend on whether claims meet opposition or surrender. We will show that agreement necessarily prevails in bargaining states. Surrender may prevail under both claim states, in one but not in the other, or opposition may occur in both. We will prove that only the first and the third scenario exclude each other. ${ }^{6}$ We say that $i$ 's claim $c_{i}$ is relevant at a given equilibrium $\sigma$, if it pays $i$ at least as much as one period of confrontation; that is $c_{i} \geq \delta\left(q_{i} v_{i}\left(s_{c i}\right)+\left(1-q_{i}\right) v_{i}\right)$, where $v_{i}$ denotes player $i$ 's average payoffs in bargaining states and $v_{i}\left(s_{c i}\right)$ denotes her expected payoffs in state $s_{c i}$. Formally, the following condition assures that the claims of both players are relevant. ${ }^{7}$

RC: Claims are relevant, for $i=1,2$,

$$
c_{i} \geq \max \left\{\frac{\left(1-q_{i}\right) \delta}{1-\delta q_{i}}, \frac{1}{2}\right\} .
$$

We start examining how the prevalence of agreement/surrender is linked across states. Observe than in equilibrium, the following remarks apply:

- If surrender prevails in state $s_{c i}$, then agreement is reached in state $s_{b j}$.

- If surrender prevails in states $s_{c 1}$ and $s_{c 2}$, then agreement prevails in states $s_{b 1}$ and $s_{b 2}$.

To understand the first observation, note that, in a bargaining state with 2 as proposer, a disagreement would prevail if and only if 1 preferred to reject any share that 2 were willing to propose; that is if $\delta\left(p_{1} v_{1}+\left(1-p_{1}\right) c_{1}\right) \geq 1-\delta\left(p_{1} v_{2}+\left(1-p_{1}\right)\left(1-c_{1}\right)\right)$, or equivalently $p_{1}\left(v_{1}+v_{2}\right)+\left(1-p_{1}\right) \geq \frac{1}{\delta}$, but the latter inequality cannot hold since $v_{1}+v_{2} \leq 1$ in any equilibrium. Similarly if surrender prevails in $s_{c 2}$, then

\footnotetext{
6 Consequently, the uniqueness of stationary equilibria - a standard feature in bargaining games of alternating proposals - is not assured in asymmetric environments.

$7 c_{i} \geq \frac{\delta\left(1-q_{i}\right)}{1-\delta q_{i}}$ implies that $c_{i} \geq \delta\left(q_{i} c_{i}+\left(1-q_{i}\right) v_{i}\right)$ for all $v_{i} \leq 1$; that is, a share $c_{i}$ dominates the payoff from continuation even if the payoff in the bargaining state is 1 .
} 
disagreement cannot prevail at $s_{b 1}$. Our second observation follows immediately from the first.

We therefore conclude that confrontation cannot occur in bargaining states. If there is confrontation in equilibrium, it must occur in a claim state. Is opposition possible in claim states, or do claims always induce surrender? A claim $c_{i}$ cannot induce surrender when the share obtained upon surrender, $1-c_{i}$, is bounded above by the expected gains of an additional period of confrontation. That is, when

$$
1-c_{i}<\delta\left(q_{i} v_{j}\left(s_{c i}\right)+\left(1-q_{i}\right) v_{j}\right),
$$

where $v_{j}\left(s_{c i}\right)$ denotes j's expected payoffs in $s_{c i}$. If (2) holds opposition prevails, so expected payoffs $v_{j}\left(s_{c i}\right)$ and $v_{i}\left(s_{c i}\right)$ must solve $v_{j}\left(s_{c i}\right)=\delta\left(q_{i} v_{j}\left(s_{c i}\right)+\left(1-q_{i}\right) v_{j}\right)$ and $v_{i}\left(s_{c i}\right)=\delta\left(q_{i} v_{i}\left(s_{c i}\right)+\left(1-q_{i}\right) v_{i}\right)$; therefore $v_{j}\left(s_{c i}\right)=\frac{\left(1-q_{i}\right) \delta v_{j}}{1-\delta q_{i}}$ and $v_{i}\left(s_{c i}\right)=$ $\frac{\left(1-q_{i}\right) \delta v_{i}}{1-\delta q_{i}}$. Substituting the expected payoffs in (2), we obtain that the necessary and sufficient condition for surrender at $s_{c i}$ is

$$
1-c_{i} \geq \frac{\left(1-q_{i}\right) \delta v_{j}}{1-\delta q_{i}} .
$$

Writing

$$
\phi_{i}\left(v_{j}\right) \equiv \frac{1-c_{i}-\delta v_{j}}{\delta\left(1-c_{i}-v_{j}\right)},
$$

condition (3) is equivalent to $q_{i} \geq \phi_{i}\left(v_{j}\right)$; in other words, the claim "must not be merely transient," 8 it must persist at least with probability $\phi_{i}\left(v_{j}\right)$. If claims are too temporary then it pays to the other side to resist them and hope for military success to reverse the situation back to a bargaining state. ${ }^{9}$ Then it follows (see the Appendix for a detailed argument) that confrontation prevails only in claim states. This completes the proof of our first proposition:

Proposition 1 Assume RC. In equilibrium the following hold:

1. Persistent claims award advantage in claim states, player $j$ surrenders and the split $\left(c_{i}, 1-c_{i}\right)$ is imposed if and only if $q_{i} \geq \phi_{i}\left(v_{j}\right)$.

2. Confrontation only in claim states. Termination, by agreement or surrender, is immediate unless a claim state occurs and $q_{i} \leq \phi_{i}\left(v_{j}\right)$.

Proposition 1 implies that any equilibrium profile must be one of the following three: (a) A confrontation profile, where agreement is reached in bargaining states, and confrontation prevails otherwise. (b) A peaceful profile, where agreement or surrender occurs at all states. (c) An $i$-advantage profile, where agreement or surrender occurs in all states except $s_{c j}$.

\footnotetext{
8 'If the enemy is to be coerced you must put him in a situation that is even more unpleasant than the sacrifice that you call on him to make. The hardships of that situation must not of course be merely transient. Otherwise the enemy would not give in but would wait for things to improve' (Clausewitz 1976).

9 Note that $\phi_{i}\left(v_{j}\right)$ is strictly increasing in $v_{j}$ and satisfies $0<\phi_{i}\left(v_{j}\right)<1$, if and only if $\delta v_{j} \geq 1-a_{i}$.
} 
The complete characterization of equilibria in general, non symmetric, environments involves straightforward but rather tedious algebra. We present it as Proposition 5 in the Appendix. Here we concentrate in symmetric environments; that is those satisfying: SYM Strengths are symmetric; for $i=1,2, c_{i}=c, q_{i}=q$ and $p_{i}=p$.

Under SYM an equilibrium cannot be an $i$-advantage profile; and the equilibrium expected payoffs at bargaining states are $v=\frac{1}{2}$. Therefore, in claim states, surrender prevails if and only if $q \geq \phi\left(\frac{1}{2}\right)=\frac{\delta / 2-(1-c)}{\delta(c-1 / 2)}$. Then a unique equilibrium exists and it is easily described:

Proposition 2 Equilibrium in symmetric environments with complete information. Under RC and SYM there is a unique equilibrium.

1. When $q \geq \frac{\delta / 2-(1-c)}{\delta(c-1 / 2)}$, the equilibrium is a peaceful profile: In state $s_{b i}$, i offers to $j$ a share $\delta\left[p \frac{1}{2}+(1-p)(1-c)\right]$ and she accepts; in state $s_{c i}, j$ surrenders and $i$ 's claim of share $c$ is imposed.

2. When $q<\frac{\delta / 2-(1-c)}{\delta(c-1 / 2)}$, the equilibrium is a confrontation profile: In state $s_{b i}, i$ offers to $j$ a share $\frac{\delta}{2}\left[p+(1-p) \frac{(1-q) \delta}{(1-\delta q)}\right]$ and she accepts; in state $s_{c i}$, confrontation prevails.

This proposition shows that the persistence of claims awards an advantage in war but not necessarily their size. When persistence is high so the equilibrium profile is peaceful, parties can appease their opponent with lower offers compared to the case where claim states do not exist, i.e. $p=1$. But when persistence is low enough to induce a confrontation equilibrium, claims are met with opposition and because they are too temporary, bigger concessions take place in bargaining states compared to when claims do not take place. On the other hand, note that $\phi\left(\frac{1}{2}\right)$ is increasing in $c$ so sizeable claims are more likely to meet opposition; thus players prefer to avoid them when they are in a bargaining state. This follows a simple but fundamental principle already advised in 510 BC in Sun Tzu's Art of War: "Do not press a desperate foe too hard."

As long as the game starts in a bargaining state, an agreement prevails immediately and claims are never raised. Still, if the game begins in a claim state and persistence $q$ is relatively low, there is confrontation until the claim is dismissed and a bargaining state arises. In a nutshell, under complete information, from a bargaining state "one would never need to use the physical impact of the fighting forces - comparing figures and their strength would be enough." (Clausewitz 1976, p. 76).

The fact is, however, that in real conflicts parties do resort to confrontation attempting to raise claims, expecting that these will be imposed quickly. But demands often meet resistance and frequently reverse. Why would then rational agents engage in confrontation to attempt establishing a claim that might eventually prove so disadvantageous? We give an answer this question in the next section, as we extend our model to account for uncertainty and asymmetric information.

\section{Uncertainty and asymmetric information}

According to Blainey a common trait of wars is that the two parties "were persuaded to fight because most of their leaders were excessively optimistic and impatient men, 
and persuaded to cease fighting because those leaders, having failed, were replaced by more cautious men." (Blainey 1973, p. 123). We propose a formal set up in which Blainey's description holds precisely. We extend our model to address situations with uncertainty and asymmetric information and show that in these circumstances, confrontations might arise (and persist) along the equilibrium path even if the initial state is a bargaining state.

Our basic assumption is that the probabilities by which players sustain the commitment to their claims are unknown a priori; they have a random value that is realized only after claims are established. In a bargaining state, when a player considers whether to reject an offer, she has some private information about the strength of her potential claim, but she learns the precise value of this strength only if, and after, the claim is established. We assume that there are two types of players, that we name hostile and lenient, and that types are private information. A hostile type draws the persistence of her claims from a distribution biased towards high values; since she expects that her claim will be highly persistent and induce the opponent's surrender, she is more inclined to engage in confrontation and consequently is more demanding in bargaining states. A lenient type, expecting that her claims will have low persistence and induce opposition, is not inclined to confrontation and therefore accommodates to lower offers.

An offer is separating if it is acceptable to a lenient opponent but unacceptable to a hostile opponent; a pooling offer is one acceptable by both types. Suppose that the proposer makes a separating offer; this triggers war if the responder turns out to be hostile. Running the risk of war may well be ex-ante optimal (vis à vis to a pooling offer) when the probability of facing a lenient opponent is high enough. Hence separating offers are an equilibrium phenomenon when the proposer is an optimist-her prior beliefs assign high probability to the opponent being lenient-opening the door to war if the responder is a hostile type. Confrontation leads to a claim state with positive probability; upon this event the persistence of the claim is learned. If such persistence turns out to be high, the (initial) proposer must surrender. But even a hostile type, that ex ante expects a high persistence, may get a low draw. Then both players realize that reality has not matched their (rational) expectations, but they are stuck in confrontation until the claim is dismissed.

We will consider a symmetric environment where $q_{1}$ and $q_{2}$ are random variables whose value is realized only after the respective claim is established. After a player rejects a proposal and her claim state occurs, the probability to defend the claim is publicly observed and it remains constant over time as long as the game remains in the same state; if the game returns to a bargaining state, future realizations of $q_{i}$ are drawn independently. With this assumption, we do not impose strengths to be constant as often done in the literature, and we can also account for the inherent randomness of war.

We assume that agents have private information on the distribution function of their own $q_{i}$. Each period that the game is in a bargaining state, players privately observe their type (the distribution of $q_{i}$ ) for that period. Formally we assume:

U1 $c_{1}=c_{2}=c>\frac{1}{2}$ and $p_{1}=p_{2}=p$, and these are known.

U2 There are two types of players, $\tau_{i} \in\{l, h\}$, at each $s_{t}=s_{b j}$ types are drawn independently with probability 


$$
\operatorname{Pr}\left(\tau_{i}=l \mid s_{t}=s_{b j}\right)=\lambda, \quad 0<\lambda<1
$$

and realized types are private information.

U3 $q_{i}$ is drawn with distribution $F^{\tau_{i}}$ at each $s_{t}=s_{c i}$ such that $s_{t-1}=s_{b j}$; then it becomes public and remains constant as long as the claim state persists.

U4 $F^{h}$ first order stochastically dominates $F^{l}: F^{h}(q) \leq F^{l}(q)$ for all $q \in[0,1]$.

Assumptions U1, U2 and $\mathbf{U 3}$ are for simplicity. The first two could be relaxed (at non-negligible notational and expositional cost) to account for larger type sets, asymmetries and uncertainty on $p$ and $c$, or serial correlation. Assumption U3 could also be relaxed to allow that $i$ retains some information advantage on $q_{i}$ after state $s_{c i}$ is realized, assuming that agents learn their own $q_{i}$ quickly while opponents must learn it by the evidence that the claim persists. This extension would deliver equilibrium histories where agents initially oppose claims but eventually surrender. $\mathbf{U} \mathbf{4}$ is the crucial assumption.

A system of beliefs for player $i, \pi_{i}$, maps histories into probability distributions over the types of player $j$. A perfect Bayesian equilibrium is an assessment $(\sigma, \pi)$ such that, $\sigma$ is a pair of strategies that are best response to each other at each history, and $\pi$ is a belief profile consistent with Bayes' rule. At a Markov strategy actions depend only on the state, the current beliefs and the current offer. Henceforth the term equilibrium refers to perfect Bayesian equilibrium in Markov strategies. Observe that an equilibrium is fully characterized by specifying proposals and acceptance/surrender thresholds for each type at each state. Note that the system of beliefs does not need to be specified beyond Bayes Rule because, at any off the equilibrium history that is not terminal, either a claim state is attained and $q$ is fully revealed; or the game remains in the bargaining state and new types are drawn - in which case players must believe that their opponent is lenient with probability $\lambda$.

Fix an equilibrium and let $v$ denote the ex-ante (before types are drawn) expected gains of players in bargaining states. (Note that, if rejections occur with positive probability, $v<\frac{1}{2}$ ). Observe that in state $s_{c i}$ if the probability that $i$ maintains her claim one more period is sufficiently small disagreement prevails: Indeed, by the same argument used to prove Proposition 1 we know that if state $s_{c i}$ occurs the game stays in confrontation as long as $q_{i} \leq \widehat{q}$, where $\widehat{q}=\phi(v)$ [recall that $\phi(v)$ is determined by Eq. (4)]. Otherwise, for $q_{i}>\widehat{q}$, player $j$ surrenders and the split $(c, 1-c)$ is imposed. ${ }^{10}$

The equilibrium is pooling-so the first proposal is accepted regardless of the responder's type and immediate agreement prevails - if and only if the probability that players are of lenient type is not too high. Otherwise, the equilibrium is separating. Along the separating equilibrium play proceeds as follows. Player $i$ makes an offer that leaves $j$ indifferent between acceptance and rejection if she is lenient (and that a hostile $j$ strictly prefers to reject). Upon rejection, with probability $p$ a new round of bargaining follows whereas the game enters state $s_{c j}$ with probability $1-p$. If state $s_{c j}$ is realized, then the value of $q_{j}$ is observed by both parties. Immediate surrender to shares $(c, 1-c)$ follows if and only if $q_{j}$ satisfies $q_{j} \geq \widehat{q}$; otherwise confrontation

$\overline{10 \text { Note that } 0<\widehat{q}<1 \text { only if } c}+\delta v>1$. 
continues until the claim is dismissed. At a new bargaining state, players observe their new type, a new separating offer is made, and so on.

For a given equilibrium with ex-ante expected gains $v$, we let $r^{l}(v)$ and $r^{h}(v)$ denote the responder's expected gains upon rejection in state $s_{b i}$, respectively for a lenient and a hostile responder. Also, $R^{h}(v)$ denotes the proposer's continuation value when her opponent rejects and the updated belief induced by rejection assigns probability 1 to the hostile type. Now, define $\lambda_{v}$ as the ratio:

$$
\lambda_{v} \equiv \frac{1-r^{h}(v)-R^{h}(v)}{1-r^{l}(v)-R^{h}(v)},
$$

and we will refer to $\lambda_{v=1 / 2}$ as the optimism threshold.

We are now ready to describe the unique equilibrium:

Proposition 3 Equilibrium in symmetric environments with private information. Under assumptions $\mathbf{U 1 - U 4}$ there is a unique equilibrium outcome.

1. If the ex-ante probability of facing a lenient type exceeds the optimism threshold, that is $\lambda>\lambda_{1 / 2}$, then the equilibrium is separating. For all $t$, in state $s_{b i}, i$ offers $x^{*}=r^{l}\left(v^{*}\right)$ and $j$ accepts only if $\tau_{j}=l$. If $\tau_{j}=h$ and $s_{t+1}=s_{c j}$ player $i$ surrenders granting $c$ to $j$ if $q_{j} \geq \phi\left(v^{*}\right)$; for $q_{j}<\phi\left(v^{*}(\lambda)\right)$ confrontation prevails at all $t+k$ until $s_{t+k}=s_{b i}$.

2. Otherwise, the equilibrium is pooling. For all $t$, in state $s_{b i}$, $i$ offers $y^{*}=r^{h}\left(\frac{1}{2}\right)$ and $j$ accepts.

In bargaining states war starts because the proposer's optimism, expecting a lenient responder with high probability, is not confirmed; it continues in claim states because the realized persistence disappoints the optimist belief of the hostile type. The former effect is the well-known risk-return trade-off in the literature on bargaining and war (Sanchez-Pages 2011). The latter is novel to our model; it is due to the commitment associated with claim states. In summary, war occurs when reality disappoints the proposer's optimism; and persists longer when both agents have optimist (rational) expectations that are not realized ex-post.

\subsection{Equilibrium histories: types of wars}

It is now immediate that when $\lambda>\lambda_{1 / 2}$, so that a separating equilibrium prevails, a great variety of equilibrium histories are possible, including prolonged confrontation and fortune reversals. Three categories of wars are possible:

1. Stalemated war An agreement $\left(\frac{1}{2}, \frac{1}{2}\right)$ does not prevail until $t=k>1$. Prior to agreement $k-1$ proposals meet rejection because a hostile responder is drawn but neither side ever raised a claim, at $t=k$ the responder type is lenient and agreement prevails. 
2. War with victory A concession to $(c, 1-c)$ prevails at $t=k+1$. After sequence of $k \geq 1$ rejections in the bargaining state the game enters a claim state at $k+1$, then upon the observation that $q \geq \hat{q}$ the opponent surrenders. ${ }^{11}$

3. Fortune reversal War prevails at least for $t=k+n$ periods; from $t=0$ to $k \geq 1$ proposals meet rejection, a claim is established at $t=k+1, q$ is low, the claim is opposed and it persists for $n$ periods. The continuation might lead to immediate agreement or to any history of type 1,2 or 3 .

Stalemated wars end in a negotiated settlement. These account for around $65 \%$ of interstate wars (Leventoglu and Slantchev 2007). If rejection of proposals does not imply necessarily the outbreak of hostilities, this equilibrium outcome would also account for disputes, such as the Cuban Missiles Crisis or the 2007 North-Korea nuclear crisis, that did not escalate into war.

Fortune reversals are conflicts in which initial claims are reversed and war proves to be a disaster to the party that attempted to establish them. In the summer of 480 BC Xerxes was about to impose his advantage over Athens: the Persian alliance with Carthage assured control over the Greek colonies in Sicily and many of the smaller Greek states were eager to settle peacefully. Still Athens refused to yield and fortunes were reversed at Salamis. Napoleon's Russian campaign of 1812 successfully reached Moscow, yet it failed "because the Russian government kept its nerve and the people remained loyal and steadfast" (Clausewitz 1976, p. 628). In the summer of 1940 Hitler was celebrating victory and awaiting Churchill to sue for peace; he did not, and events took a very different course. Argentina's invasion of the Falkland in April of 1982 and Iraq's invasion of Kuwait in 1990 also fall under this category. Wars such as the Korean and the Vietnam wars, where parties alternated claims but none was imposed at the end, are combinations of fortune reversals and stalemated conflicts.

For realizations of the parameters that deliver a separating equilibrium, the probability of an immediate agreement is $\lambda$; and the probability of a stalemated confrontation is $(1-\lambda)(1-p)$ each period. To evaluate the ex-ante likelihood of victories and fortune reversals we must measure $\operatorname{Pr}(q \geq \hat{q})$, which requires a specification of $F^{l}(q)$ and $F^{h}(q)$. For simplicity and for the remainder of the paper, we will assume that $F^{l}(q)$ is a degenerate distribution and $F^{h}(q)$ a two point distribution; the lenient type draws a low $q<1 / 2$ with probability 1 , and the hostile type draws the low $q$ with probability $1-\alpha$ and a high $q=1$, with probability $\alpha$. Under these assumptions, the ex-ante probability of a war with victory (fortune reversals) is $(1-\lambda) \alpha p((1-\lambda)(1-\alpha) p)$ per period.

\subsection{The likelihood of war}

War occurs with positive probability only when the optimism threshold is low enough, that is $\lambda_{1 / 2}<\lambda<1$. When this inequality holds, the probability that war starts is

\footnotetext{
11 The assumption that $q$ becomes public immediately when the claim state is realized rules out equilibria where claims are initially challenged but eventually prevail. Such histories might occur in equilibrium under the assumption that agents learn their own $q$ quickly while opponents must learn it by the evidence that the claim persists.
} 
Fig. $1 \lambda_{1 / 2}$ as a function of $\delta$ for $c=0.65$ and 0.85
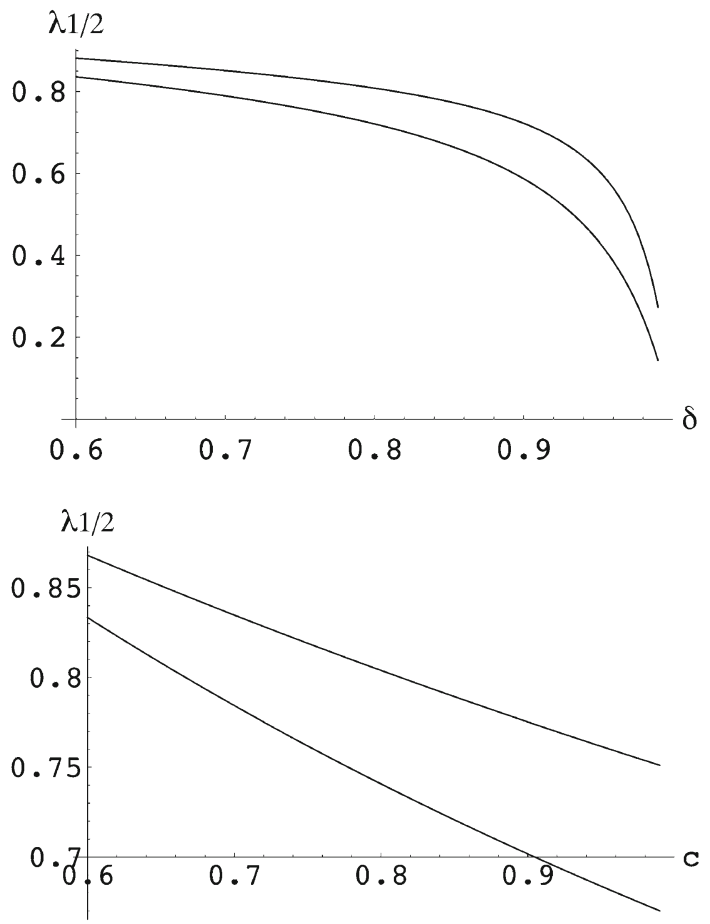

Fig. $2 \lambda_{1 / 2}$ as a function of $c$ for $\delta=0.7$ and 0.8

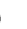

$1-\lambda>0$ at every period that the game spends in the bargaining state. Consequently, to evaluate how changes in the environment translate into changes on the probability that war starts, we must examine $\lambda_{1 / 2}=\frac{1-r^{h}(1 / 2)-R^{h}(1 / 2)}{1-r^{l}(1 / 2)-R^{h}(1 / 2)}$, as a function of the parameters $\delta, p, c$, and $\alpha$.

The values of $1-p$ and $\alpha$ measure the strength of players upon confrontation; greater values translate in increases of the agents' continuation values. Consequently, $\frac{\partial \lambda_{1 / 2}}{\partial p} \geq 0, \frac{\partial \lambda_{1 / 2}}{\partial \alpha} \leq 0$, with strict inequality whenever $\lambda_{1 / 2}<1$. Evaluating $\frac{\partial \lambda_{1 / 2}}{\partial \delta}$ and $\frac{\partial \lambda_{1 / 2}}{\partial c}$ requires some algebra, but it is not hard to check that, $\lambda_{1 / 2}$ is strictly decreasing both in $\delta$ and in $c$. Figures 1 and 2 display $\lambda_{1 / 2}$ as a function of $\delta$ and $c$ for $\alpha$ and the low $q$ fixed at $1 / 2$.

We summarize these observations in the following proposition:

Proposition 4 The optimism threshold $\lambda_{1 / 2}$ decreases, so the separating equilibrium (and war) prevails for a wider range of prior belief $\lambda$, whenever one of the following takes place:

1. Claims become more extreme.

2. The claim state arises with greater probability.

3. The hostile type expects greater persistence of claims.

4. Per-period losses decrease.

For $F^{l}(q)$ and $F^{h}(q)$ fixed, the size of claims $c$ and the cost of confrontation $1-\delta$, have impact only over the threshold $\lambda_{1 / 2}$, and not on the effective probability of war 
$1-\lambda$. Hence, small changes in $c$ or $\delta$ are inconsequential. However, bigger changes can either drop the probability of confrontation from $1-\lambda$ to 0 , or bring it up from 0 to $1-\lambda$. For example, let $q=\alpha=1 / 2, \lambda=0.83, c=0.8$, and $\delta=0.8$. In this environment $\lambda_{1 / 2}=0.79<\lambda=0.83<1$; so war occurs with probability $1-\lambda=0.17$. A small change in $\delta$ has an effect on $\lambda_{1 / 2}$ but, as long as the inequality $\lambda_{1 / 2}<\lambda=0.83$ is maintained, it has no impact in the probability of war. However, with a change to $\delta>0.7$, the inequality is reversed, and with $\lambda_{1 / 2}>\lambda$ the probability of war drops to zero. Thus, a sufficient increase in the costs of confrontation can eliminate the possibility of war. This is consistent with the idea that the steady decrease observed in the number of wars since 1816 (Gleditsch 2004, p. 243) might be due to the development and use of more deadly technologies of warfare.

Likewise, small changes in $c$ have no impact in the probability of war but a sufficient decrease in $c$, say to $c<0.7$, drops the probability of war to zero. Interpreting $c$ as the value of a special landmark, our results are consistent with a established fact, especially in the context of civil wars (Ross 2003), that links the prevalence of war with the presence of natural resources. If, alternatively, we interpret $c$ as the salience of the issue provoking the dispute, our results are consistent with the fact that satisfaction with the status quo (low $c$ ) decreases the likelihood of conflict between Major Powers (Lemke and Reed 2001).

\subsection{The losses and duration of war}

The difference between potential gains and expected payoffs in equilibrium measures the expected losses caused by war. Under a pooling equilibrium the ex-ante expected payoff is $v=1 / 2$ for each agent and therefore no loss is incurred. In a separating equilibrium the expected loss is $1-2 v>0$.

In the appendix we establish that under the present specification

$$
v=\frac{1}{2} \frac{\lambda+(1-\lambda) 2 g}{1-(1-\lambda) h}
$$

where $h \equiv \delta\left(p+\frac{(1-p) \delta(1-q) \alpha}{1-\delta q}\right)$ and $g \equiv \frac{\delta(1-p)(1-\alpha)}{2}$. It is easily checked that $2 g+h<$ 1 , and therefore $\frac{\partial v}{\partial \lambda}=\frac{1}{2} \frac{1-h-2 g}{(1-h+h \lambda)^{2}}>0$. Thus, the worse outcomes are attained at the lower values of $\lambda$ that satisfy $\lambda>\lambda_{1 / 2}$. Figure 3 displays the expected gains as functions of $\lambda$ for $c=0.7, \alpha=p=q=0.5$, and $\delta=0.9$. On the other hand, $v$ increases in $\delta$. Figure 4 displays the expected gains as a functions of $\delta$ for $c=0.7, \alpha=p=q=0.5$, and $\lambda=0.7$. It is also immediate that $v$ increases in $p$ and decreases in $q$ and $\alpha$. Let us emphasize that the qualitative features of this illustrative example are general.

Finally, it is straightforward to see that when $\lambda \geq \lambda_{1 / 2}$, other parameters fixed, the probability of a "War with victory" $\operatorname{Pr}(q \geq \hat{q})$ is greater the lower $\lambda$, and the lower $c$. This has two implications: First, that shorter wars are more likely, i.e. $\operatorname{Pr}(q \geq \hat{q})$ is higher, when the probability of drawing a hostile type is greater. And second, that fortune reversals are more likely, i.e. $\operatorname{Pr}(q \geq \hat{q})$ is lower, and thus wars last longer, when the value of claims increases. The latter effect is consistent with the fact that 
Fig. 3 Expected gains as a function of $\lambda, \delta=0.9$

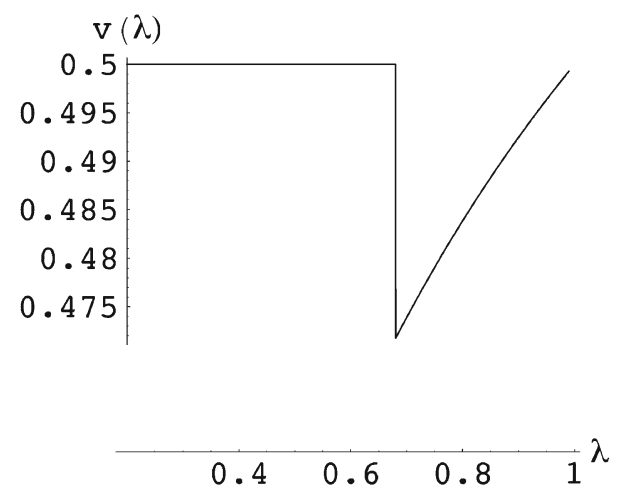

0.70 .750 .80 .850 .90 .95

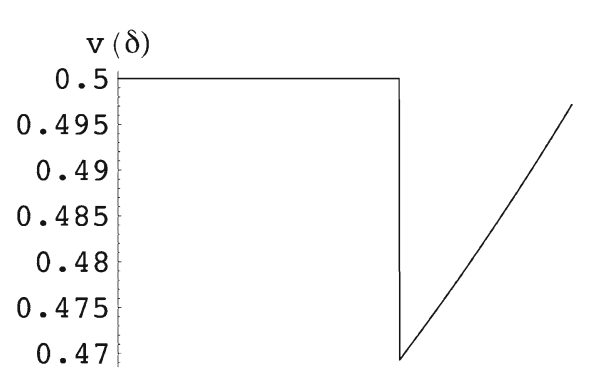

$\delta$
Fig. 4 Expected gains as a function of $\delta$

civil wars in resource-rich nations are harder to end (Ross 2003) and with the fact that higher issue salience worsens the outcome of war for initiator countries (Slantchev 2004).

\section{Final remarks}

We have presented a model of bargaining and war where the set of admissible agreements follows a Markov process. Our contribution points out that, when the ability to impose claims is linked to the use of force, uncertainties and informational asymmetries may fuel prolonged episodes of confrontation. The richness of equilibrium outcomes (despite the equilibrium being unique) can account for the wide variety of patterns observed in wars. Our comparative statics are also consistent with some empirical studies on the onset and termination of interstate wars.

We carried out this analysis for the simplest scenario, assuming that there are only two states, and that transitions are governed by stationary probabilities. Real conflicts have immense sets of states and their transition probabilities are hardly stationary. Nevertheless the qualitative nature of our results does not rely on our drastic simplifications. Results would remain unchanged if the responder chose between acceptance, rejection without confrontation, and rejection with confrontation. At the cost of increased complexity we could also consider larger state sets-for example a state 
in which both players hold incompatible claims; or we could admit richer transitions probabilities. The cost of confrontation could also be asymmetric across players and or states. Our results are robust to such alternative formulations. We hope they can provide useful intuitions relevant in the analysis of real, more complex, disputes and guide a revised look at the empirical evidence.

One key assumption of our analysis is that claims entail commitment to a specific division - for instance because a party attaining (temporary) control of the landmark is not free to back down and bargain unless she is defeated in confrontation. Audience costs, reputation, indivisibilities, extremism and nationalism can explain these rigidities. Still, the value of these claims and the probabilities to establish and maintain them have been assumed exogenous. In reality, however, these probabilities depend on the degree of advantage aimed by a player; as well as on the opponent's strength and claim value. An extension of our model allowing that bargaining parameters are interrelated and endogenously determined by the strategic choice of the agents will be the object of further research.

Open Access This article is distributed under the terms of the Creative Commons Attribution License which permits any use, distribution and reproduction in any medium, provided the original author(s) and source are credited.

\section{Appendix}

Proof of Proposition 1 By Eq. (1), the responder payoffs in state $s_{b i}$ are such that

$$
\begin{aligned}
& \text { if }\left(q_{1}, q_{2}\right) \ll\left(\phi_{1}\left(v_{2}\right), \phi_{2}\left(v_{1}\right)\right), \quad v_{i}^{r}=\delta v_{i}\left(p_{i}+\left(1-p_{i}\right) \frac{\left(1-q_{i}\right) \delta}{1-\gamma q_{i}}\right), \\
& \text { if }\left(q_{1}, q_{2}\right) \gg\left(\phi_{1}\left(v_{2}\right), \phi_{2}\left(v_{1}\right)\right), \quad v_{i}^{r}=\delta\left(p_{i} v_{i}+\left(1-p_{i}\right) a_{i}\right),
\end{aligned}
$$

while the proposer obtains $v_{j}^{p}=1-v_{i}^{r}$.

Clearly agreement must prevail in a state $s_{b i}$ when confrontation prevails in both claim states. Hence we only need to consider strategy profiles that yield concession in state $s_{c i}$ but not in state $s_{c j}$.

Consider first profiles that yield concession in state $s_{c 1}$ but not in state $s_{c 2}$. When 1 proposes, 2 accepts as long as her share is at least $v_{2}^{r}=\delta v_{2}\left(p_{2}+\left(1-p_{2}\right) \frac{\left(1-q_{2}\right) \gamma}{\left(1-\gamma q_{2}\right)}\right)$, and thus agreement can be attained if and only if 1 prefers to offer that share over disagreement. That is,

$$
\delta v_{1}\left(p_{2}+\left(1-p_{2}\right) \frac{\left(1-q_{2}\right) \delta}{\left(1-\delta q_{2}\right)}\right) \leq 1-\delta v_{2}\left(p_{2}+\left(1-p_{2}\right) \frac{\left(1-q_{2}\right) \delta}{\left(1-v q_{2}\right)}\right)
$$

or equivalently $v_{1}+v_{2} \leq \frac{1-\delta q_{2}}{\delta\left(\delta\left(1-q_{2}\right)+(1-\delta) p_{2}\right)}$. A condition that always holds since the second term exceeds 1 . 
Proof of Proposition 3 Fix an equilibrium. Given ex-ante expected gains at bargaining states $v$, the continuation values upon a rejection $r^{l}(v)$ and $r^{h}(v)$ are

$$
\begin{aligned}
r^{l}(v) & =\delta\left(p v+(1-p)\left[v \Phi^{l}+\left(1-F^{l}(\widehat{q})\right) c\right]\right), \\
r^{h}(v) & =\delta\left(p v+(1-p)\left[v \Phi^{h}+\left(1-F^{h}(\widehat{q})\right) c\right]\right) .
\end{aligned}
$$

where $\Phi^{\tau} \equiv \delta \int_{0}^{\widehat{q}} \frac{1-q}{1-\delta q} d F^{\tau}(q) d q$. It is a matter of simple algebra to check that $r^{h}(v)>r^{l}(v) .^{12}$ Similarly, the proposer's continuation value upon responders rejection, when the induced beliefs are $\pi$ is

$$
R^{\pi}(v)=p \delta v+(1-p) \delta\left[v \Phi^{\pi}+\left(1-F^{\pi}(\widehat{q})\right)(1-c)\right]
$$

Recall that $\lambda_{v} \equiv \frac{1-r^{h}(v)-R^{h}(v)}{1-r^{l}(v)-R^{h}(v)}$, where $R^{h}$ denotes $R^{\pi}$ when belief $\pi$ assigns probability 1 to the hostile type.

Next, we point out that at a pooling equilibrium agreement prevails for sure in the bargaining states. Assume for the sake of the argument that disagreement prevails for sure in state $s_{b i}$. It is then necessary that the proposer prefers disagreement to an agreement that the lenient responder accepts, that is $R^{\pi}(v)>1-r^{l}(v)$. However, at the hypothesized pooling equilibrium profile the beliefs of the proposer upon rejection are $G=\lambda F^{l}+(1-\lambda) F^{h}$ so that the continuation value is $R^{g}(v)=$ $\delta p v+\delta(1-p)\left[v \Phi^{g}+(1-G(\widehat{q}))(1-c)\right]$. It is then immediate to check that $v \leq \frac{1}{2}$ implies that $R^{g}(v)+r^{l}(v)<1$, a contradiction. Consequently, an equilibrium must be either a pooling equilibrium where both types accept, or a separating equilibrium where the responder accepts if and only if she is lenient.

Let us now discuss the necessary and sufficient conditions for pooling or separating equilibria. Consider first a pooling equilibrium. Since in states $s_{b i}$ the initial proposal is surely accepted, the complete symmetry of the environment implies that $v=\frac{1}{2}$. If state $s_{c i}$ occurs (off the equilibrium path) confrontation prevails for $q<\phi\left(\frac{1}{2}\right)$. Hence the responder's rejection values are uniquely given as $r^{l}\left(\frac{1}{2}\right)$ and $r^{h}\left(\frac{1}{2}\right)$. On the other hand, if a rejection were to reveal that the responder is hostile the proposer's rejection value would be $R^{h}\left(\frac{1}{2}\right)$. By hypothesis, in state $s_{b i}$, both types of responder must accept, hence the proposer must offer $y^{*}=r^{h}\left(\frac{1}{2}\right)$. At the alleged pooling equilibrium the proposer must prefer a sure payoff $1-y^{*}$ over making a lower offer, $y^{\prime}<y^{*}$, and getting acceptance only if the responder is lenient. The least that must be offered to obtain acceptance with positive probability is $y^{\prime}=r^{l}\left(\frac{1}{2}\right)$, hence it is necessary that $1-r^{h}\left(\frac{1}{2}\right) \geq \lambda\left(1-r^{l}\left(\frac{1}{2}\right)\right)+(1-\lambda) R^{h}\left(\frac{1}{2}\right)$; that is, the prior probability of the lenient type must not exceed the optimism threshold at $v=\frac{1}{2}, \lambda \leq \lambda_{\frac{1}{2}}$. In addition to necessary, this inequality is also sufficient for the existence of a pooling equilibrium: It suffices that the belief of the proposer upon (off the equilibrium) rejection assigns probability 1 to the hostile type.

$12 r^{h}(v)-r^{l}(v)=(1-p) \delta\left[v\left(\Phi^{h}-\Phi^{l}\right)+c\left(F^{l}(\widehat{q})-F^{h}(\widehat{q})\right)\right]$ and observe that the right hand side is positive if and only if $c \geq \delta v \frac{\Phi^{l}-\Phi^{h}}{F^{l}(\widehat{q})-F^{h}(\widehat{q})}$, an inequality that holds, since $c \geq \frac{1}{2}, \delta v<\frac{1}{2}$ and $\frac{\Phi^{l}-\Phi^{h}}{F^{l}(\widehat{q})-F^{h}(\widehat{q})}<1$. 
Next, consider a separating equilibrium. Note that $v<\frac{1}{2}$, because in state $s_{b i}$ the proposer offers only the rejection value of the lenient type, $x=r^{l}(v)$, which is accepted by $l$ but not by $h$. Moreover, the proposers's beliefs about $q$ upon rejection must be $F^{h}$ so that the proposer rejection value is $R^{h}(v)$. Since either player proposes with equal probability, $v$ must satisfy $v=\frac{1}{2}\left(\lambda r^{l}(v)+(1-\lambda) r^{h}(v)\right)+\frac{1}{2}\left(\lambda\left(1-r^{l}(v)\right)+\right.$ $\left.(1-\lambda) R^{h}(v)\right)$, that simplifies

$$
v=\lambda \frac{1}{2}+(1-\lambda) \frac{R^{h}(v)+r^{h}(v)}{2},
$$

Denote the solution to this equation by $v^{*}$. This solution always exists, and it is unique. (It is immediate to check that $\gamma:[0,1] \rightarrow[0,1]$, where $\gamma(v)=v-\lambda \frac{1}{2}-(1-\lambda)$ $\frac{R^{h}(v)+r^{h}(v)}{2}$, is a contraction and therefore has a unique fixed point.) Furthermore, note that $0<v^{*}<\frac{1}{2}$. In state $s_{b i}, i$ must offer $r^{l}\left(v^{*}\right)$; and this must be preferred to offering $r^{h}\left(v^{*}\right)$, i.e.

$$
\lambda \geq \lambda_{v^{*}}
$$

Therefore the necessary and sufficient condition for the existence of a separating equilibrium is that $\lambda \geq \lambda_{1 / 2}:$ since $v^{*}<\frac{1}{2}$ and $\lambda_{v}$ is strictly increasing in $v, \lambda>\lambda_{\frac{1}{2}}$ implies that $\lambda \geq \lambda_{v^{*}}$. This completes the proof.

\section{Computation of equilibrium values}

In a separating equilibrium, the ex-ante expected payoff $v$ must solve $v=\lambda / 2+(1-$ $\lambda) \frac{r^{h}(v)+R^{h}(v)}{2}$. It is easy to check that under the present specification for $F^{l}(q)$ and $F^{h}(q)$,

$$
r^{h}(v)=\delta\left[p v+(1-p)\left(\alpha \frac{v \delta(1-q)}{1-\delta q}+(1-\alpha) c\right)\right]
$$

and

$$
R^{h}(v)=\delta\left[p v+(1-p)\left(\alpha \frac{v \delta(1-q)}{1-\delta q}+(1-\alpha)(1-c)\right)\right]
$$

so that

$$
\frac{r^{h}(v)+R^{h}(v)}{2}=\delta v\left[p+(1-p) \alpha \frac{\delta(1-q)}{1-\delta q}\right]+\delta(1-p)(1-\alpha) \frac{1}{2} .
$$


Writing $h \equiv \delta\left(p+\frac{(1-p) \delta(1-q) \alpha}{1-\delta q}\right)$ and $g \equiv \frac{\delta(1-p)(1-\alpha)}{2}, v$ must solve $v=\frac{\lambda}{2}+(1-\lambda)$ $(h v+g)$. Hence

$$
v=\frac{1}{2} \frac{\lambda+(1-\lambda) 2 g}{1-(1-\lambda) h} .
$$

It is easily checked that $2 g+h<1$, and therefore $\frac{\partial v}{\partial \lambda}=\frac{1}{2} \frac{1-h-2 g}{(1-h+h \lambda)^{2}}>0$. Derivatives with respect to other parameters are immediate.

Proposition 5 Equilibria in non-symmetric, complete information, environments Under RC an equilibrium always exists. Moreover,

1. A peaceful equilibrium excludes the existence of a confrontation equilibrium. Equilibria in 1-advantage strategies and 2-advantage strategies may coexist; and these may coexist with either a peaceful equilibrium or a confrontation equilibrium.

2. The expected payoffs of player $i$ in a bargaining state under the four categories of (potential) equilibrium profiles, denoted $\sigma^{c}, \sigma^{p}, \sigma^{1}$ and $\sigma^{2}$, are:

\begin{tabular}{|c|c|c|c|}
\hline$v_{i}\left(\sigma^{p}\right)$ & $v_{i}\left(\sigma^{i}\right)$ & $v_{i}\left(\sigma^{j}\right)$ & $v_{i}\left(\sigma^{c}\right)$ \\
\hline$\frac{1-\delta p_{j}+\delta c_{i}\left(1-p_{i}\right)-\delta c_{j}\left(1-p_{j}\right)}{2-\delta\left(p_{i}+p_{j}\right)}$ & $\frac{\rho_{j}}{\rho_{j}+\lambda_{i}}$ & $\frac{\lambda_{j}}{\rho_{i}+\lambda_{j}}$ & $\frac{\rho_{j}}{\rho_{2}+\rho_{1}}$ \\
\hline
\end{tabular}

where $\rho_{i} \equiv 1-\delta p_{i}-\left(1-p_{i}\right) \frac{\left(1-q_{i}\right) \delta^{2}}{1-\delta q_{i}}$ and $\lambda_{i} \equiv 1-\delta\left(p_{i}+c_{i}\left(1-p_{i}\right)\right)$.

Remark The multiplicity of stationary equilibria opens the door to subgame perfect equilibria in which confrontation occurs in the bargaining state, provided that nonstationary strategies are allowed. Since this is a standard result we do not elaborate it further.

Proof The values of expected payoffs at bargaining states for each of the potential equilibrium strategy profiles, $\sigma^{c}, \sigma^{p}$ and $\sigma^{i}, i=1,2$, follows from straightforward algebra. It is also immediate to check that $v_{i}^{i}>\max \left\{v_{i}^{c}, v_{i}^{p}\right\}>\min \left\{v_{i}^{c}, v_{i}^{p}\right\}>v_{i}^{j}$.

Given a configuration of parameters $\left(c_{1}, c_{2}, p_{1}, p_{2}\right)$ define the sets

$$
\begin{aligned}
Q^{c} & =\left\{\left(q_{1}, q_{2}\right) \mid\left(q_{1}, q_{2}\right) \ll\left(\phi_{1}\left(v_{2}^{c}\right), \phi_{2}\left(v_{1}^{c}\right)\right)\right\}, \\
Q^{p} & =\left\{\left(q_{1}, q_{2}\right) \mid\left(q_{1}, q_{2}\right) \gg\left(\phi_{1}\left(v_{2}^{p}\right), \phi_{2}\left(v_{1}^{p}\right)\right)\right\}, \\
Q^{i} & =\left\{\left(q_{1}, q_{2}\right) \mid q_{i}>\phi_{i}\left(v_{j}^{i}\right), q_{j} \leq \phi_{j}\left(v_{i}^{i}\right)\right\} .
\end{aligned}
$$

Necessary and sufficient conditions to sustain each of the potential profiles as an equilibrium are now immediate:

1. A peaceful equilibrium exists if and only if $\left(q_{1}, q_{2}\right) \in Q^{p}$;

2. A confrontation equilibrium exits if and only if $\left(q_{1}, q_{2}\right) \in Q^{c}$;

3. An $i$-advantage equilibrium exits if and only if $\left(q_{1}, q_{2}\right) \in Q^{i}$. 
Therefore what profiles can prevail as equilibria for each parameter configuration depends on the specific geometry of $Q^{c}, Q^{p}, Q^{1}$ and $Q^{2}$. Consider first the set $Q^{p}$ since it is specially simple: Since $v_{i}^{p}$ is independent of $\left(q_{1}, q_{2}\right)$, so is $\phi_{i}\left(v_{j}\right)$ and consequently

$$
Q^{p}=\left\{\left(q_{1}, q_{2}\right) \mid\left(q_{1}, q_{2}\right) \gg\left(\widehat{q}_{1}, \widehat{q}_{2}\right)\right\},
$$

where $\widehat{q}_{i}=\phi_{i}\left(v_{j}^{p}\right)$.

On the other hand, observe that $Q^{c}$ can be expressed as

$$
Q^{c}=\left\{\left(q_{1}, q_{2}\right) \mid q_{1} \leq \varphi_{1}\left(q_{2}\right), q_{2} \leq \varphi_{2}\left(q_{1}\right)\right\}
$$

where $y=\varphi_{1}\left(q_{2}\right)$ if and only if $y$ solves $y=\phi_{1}\left(\frac{\rho_{1}(y)}{\rho_{2}+\rho_{1}(y)}\right)$, where $\rho_{i}(y) \equiv 1-\delta p_{i}-$ $\left(1-p_{i}\right) \frac{(1-y) \delta^{2}}{1-\delta y} \rho_{i}$; and analogously for $\varphi_{2}\left(q_{1}\right)$. It is straightforward to check that the functions $\varphi_{i}$ are decreasing.

Note that $Q^{c} \cap Q^{p}=\emptyset$. Indeed, since both $\varphi_{i}$ are decreasing it is straightforward to check that $\widehat{q}_{1}>\varphi_{2}\left(\widehat{q}_{2}\right)$ and $\widehat{q}_{2}>\varphi_{1}\left(\widehat{q}_{1}\right)$.

With respect to $Q^{i}$ observe that $\left(v_{i}^{i}, v_{j}^{i}\right)=\left(\frac{\rho_{j}}{\rho_{j}+\lambda_{i}}, \frac{\alpha_{i}}{\rho_{j}+\lambda_{i}}\right)$ depends only on $c_{i}$ and $q_{j}$. Hence

$$
Q^{i}=\left\{\left(q_{1}, q_{2}\right) \mid q_{i}>\psi_{i}\left(q_{j}\right), q_{j} \leq \bar{q}_{j}\right\},
$$

where $\bar{q}_{j}$ solves $q_{j}=\phi_{j}\left(v_{i}^{i}\right)=\frac{1-c_{j}-\delta \frac{\rho_{j}}{\rho_{j}+\lambda_{i}}}{\delta\left(1-c_{j}-\frac{\rho_{j}}{\rho_{j}+\lambda_{j}}\right)}$ and $\psi_{i}\left(q_{j}\right)$ is $\phi_{i}\left(v_{j}^{i}\right)=\frac{1-c_{i}-\delta \frac{\lambda_{i}}{\rho_{j}+\lambda_{i}}}{\delta\left(1-c_{i}-\frac{\lambda_{i}}{\rho_{j}+\lambda_{i}}\right)}$. Since $v_{i}^{i}>v_{i}^{p}$ we obtain that $\bar{q}_{j}>\widehat{q}_{j}$. Moreover, since $\phi_{i}$ is increasing, $\psi_{i}\left(q_{j}\right)$ decreases in $q_{j}$ and furthermore $\varphi_{i}\left(q_{j}\right)>\psi_{i}\left(q_{j}\right)$.

We have thus shown that $Q^{i} \cap Q^{p} \neq \varnothing, Q^{i} \cap Q^{c} \neq \emptyset$ and $q \notin Q^{p} \cup Q^{c} \Leftrightarrow q \in$ $Q^{1} \cup Q^{2}$. Hence, an equilibrium always exists, it is generally not unique since different types of equilibria (up to three) may coexist for some parameter configurations; yet a peaceful equilibrium and an confrontation equilibrium never coexist.

\section{References}

Banks JS (1990) Equilibrium behavior in crisis bargaining games. Am J Political Sci 34:599-614

Bester H, Warneryd K (2006) Conflict and the social contract. Scand J Econ 108(2):231-249

Bevia C, Corchon L (2010) Peace agreements without commitment. Games Econ Behav 68:469-487

Blainey G (1973) The causes of war. Free Press, New York

Crawford V (1982) A model of disagreement in bargaining. Econometrica 50:607-637

Fearon JD (1994) Domestic political audiences and the escalation of international disputes. Am Political Sci Rev 88(3):577-592

Fearon JD (1995) Rationalist explanations for war. Int Organ 49:379-414

Filson D, Werner S (2002) Bargaining model of war and peace: anticipating the onset, duration and outcome of war. Am J Political Sci 46:819-838

Gleditsch K (2004) A revised list of wars between and within independent states, 1816-2002. Int Interact 30:231-262

Goddard SE (2006) Uncomman Ground: indivisible territory and the politics of legitimacy. Int Organ 60:3568 
Hassner R (2003) To have and to hold: conflicts over sacred space and the problem of indivisibility. Secur Stud 12:1-33

Jackson MO, Morelli M (2007) Political bias and war. Am Econ Rev 97(4):1353-1373

Lemke D, Reed W (2001) War and rivalry among great powers. Am J Political Sci 45(2):457-469

Leventoglu B, Slantchev B (2007) The armed peace: a punctuated equilibrium theory of war. Am J Political Sci 51(4):755-771

Leventoglu B, Tarar A (2008) Does rivate information lead to delay or war in crisis bargaining? Int Stud Q 52(3):533-553

Merlo A, Wilson C (1995) A stochastic model of sequential bargaining with complete information. Econometrica 63:371-399

O’Neil B (1999) Honor, symbols and war. Michigan University Press, Ann Arbor

Powell R (1996) Bargaining in the shadow of power. Games Econ Behav 15:255-289

Powell R (1999) In the shadow of power. Princeton University Press, Princeton

Powell R (2004) Bargaining and learning while fighting. Am Political Sci Rev 48:344-361

Powell R (2006) War as a commitment problem. Int Organ 60:169-204

Ross ML (2003) Oil, drugs and diamonds: the varying role of natural resources in civil war. In: Ballentine K, Sherman J (eds) The political economy of armed conflict: beyond greed and grievance. Lynne Rienner, Boulder

Sanchez-Pages S (2009) Conflict as a part of the bargaining process. Econ J 119(539):1189-1207

Sanchez-Pages S (2011) Bargaining and conflict with incomplete information. In: Garfinkel M, Skaperdas S (eds) The Oxford handbook of the economics of peace and conflict. Oxford University Press, Oxford (forthcoming)

Schelling TC (1960) Strategy of conflict. Harvard University Press, Cambridge

Schelling TC (1966) Arms and influence. Yale University Press, New Haven and London

Schultz KA (1998) Domestic opposition and signaling in international crises. Am Political Sci Rev 92(4):829-844

Slantchev B (2003) Principle of convergence in wartime negotiations. Am Political Sci Rev 47:621-637

Slantchev B (2004) How initiators end their wars: the duration of warfare and the terms of peace. Am J Political Sci 48(4):813-829

Smith A (1998) Fighting battles, winning wars. J Confl Resolut 43:301-320

Smith A, Stam AS (2004) Bargaining and the nature of war. J Confl Resolut 48:783-813

Sun T (1988) In: J Clavell (ed) The art of war. New York

Toft MD (2006) Issue indivisibility and time horizons as rationalist Explanations for war. Secur Stud 15: 34-69

von Clausewitz C (1976) In: Howard M, Paret P (eds) On war. Princeton University Press, Princeton

Wagner RH (2000) Bargaining and war. Am J Political Sci 44:469-484

Wittman D (1979) How a war ends: a rational model approach. J Confl Resolut 23(4):743-763 